\title{
Total glucosides of peony ameliorates Sjögren's syndrome by affecting Th1/Th 2 cytokine balance
}

\author{
GUOLIN WU ${ }^{1}$, NAYUAN WU ${ }^{1}$, TIANYI LI ${ }^{2}$, WENWEN LU ${ }^{1}$ and GUOYOU YU ${ }^{1}$ \\ ${ }^{1}$ Department of Chinese Traditional Medicine, The First Affiliated Hospital, College of Medicine, Zhejiang University, \\ Hangzhou, Zhejiang 310003; ${ }^{2}$ Function Institute of Basic Medical College, Zhejiang Chinese Medical University, \\ Hangzhou, Zhejiang 310053, P.R. China
}

Received April 16, 2015; Accepted November 25, 2015

DOI: $10.3892 /$ etm.2016.3016

\begin{abstract}
The present study aimed to investigate the molecular mechanisms underlying the effects of total glucosides of peony (TGP) in the treatment of Sjögren's syndrome (SS). A total of 40 mice with SS were evenly assigned into four groups, including: Control group; TGP group, receiving $1 \mathrm{mg}$ TGP daily; hydroxychloroquine (HCQ) group, receiving $0.25 \mathrm{mg}$ HCQ daily; and a combined group, receiving $1 \mathrm{mg}$ TGP and $0.25 \mathrm{mg}$ HCQ daily. After 8 weeks, quantitative polymerase chain reaction and an enzyme-linked immunosorbent assay were used to detect the levels of interferon- $\gamma($ IFN- $\gamma$ ), interleukin-4 (IL-4), Fas and FasL in each group of mice. In addition, immunohistochemical analysis was used to determine the expression levels of IFN- $\gamma$ and IL-4. IFN- $\gamma$, IL-4, Fas and FasL levels were significantly increased in the control group compared with the other three groups $(\mathrm{P}<0.05)$. Furthermore, the expression levels of these factors were reduced in the combined group in comparison with the HCQ group $(\mathrm{P}<0.05)$. The ratios of IFN- $\gamma$ to IL-4 were decreased in the TGP and combined groups compared with the control group $(\mathrm{P}<0.05)$. The present results indicate that TGP ameliorates SS by affecting the Th1/Th2 cytokine balance and decreasing the expression levels of IFN- $\gamma$, IL-4, Fas and FasL. Therefore, TGP may represent a potential novel therapeutic agent for the treatment of SS.
\end{abstract}

\section{Introduction}

Total glucosides of peony (TGP) are the primary active ingredients of Paeoniaceae paeonia and have been widely used in the treatment of Sjögren's syndrome (SS) $(1,2)$. Previous studies

Correspondence to: Dr Guoyou Yu, Department of Chinese Traditional Medicine, The First Affiliated Hospital, College of Medicine, Zhejiang University, 79 Qingchun Road, Hangzhou, Zhejiang 310003, P.R. China

E-mail: yuguoyou_ke2@126.com

Key words: total glucosides of peony, Sjögren's syndrome, NOD mice, Th1/Th2, Fas, FasL have demonstrated that TGP is able to attenuate the symptoms exhibited by patients with SS, including a dry mouth and eyes, and the SS-associated decrease in erythrocyte sedimentation rate (ESR) (3-5). However, the molecular mechanisms underlying the activity of TGP in SS therapy remain unclear. The levels of Th1-secreted interferon- $\gamma($ IFN- $\gamma$ ) and Th2-secreted interleukin-4 (IL-4) are positively correlated with the extent of lymphocytic infiltration in the labial glands of patients with SS (6), and the ratio of IFN- $\gamma$ to IL-4 indicates the Th1/Th2 cytokine balance (7).

The Fas and Fas ligand (FasL) system is an important signaling pathway for inducing apoptosis in cells (8), and Fas/FasL-mediated apoptosis is reported to be associated with cancer cell death (9). Fas antigen and its ligand FasL have an important role in peripheral $\mathrm{T}$ cell clearance and the cytotoxicity of cytotoxic T lymphocytes (CTLs) (10). It is established that activated $\mathrm{T}$ cells and CTLs are critical for modulation of the immune response, meaning that the function of Fas and FasL are also crucial to immune reactions (11).

Furthermore, the levels of Fas and FasL in the submandibular glands have been observed to be significantly increased in SS mice compared with control mice (12). In the labial glands of patients with SS, the levels of Fas and FasL are associated with IFN- $\gamma$ and IL-4 levels and are positively correlated with lymphocytic infiltration (13). Previous results thus indicate that an increase in the levels of IFN- $\gamma$, IL-4, Fas and FasL may be crucially involved in the pathogenesis of SS.

To clarify the molecular mechanism underlying the efficacy of TGP for the treatment of SS, the present study evaluated the effects of TGP on the levels of IFN- $\gamma$, IL-4, Fas and FasL in serum and in the submandibular glands in an SS mouse model.

\section{Materials and methods}

Animals. A total of 40 female, 8-week-old, non-obese (weight, 25-35 g) diabetic (NOD) mice with SS were provided by Shanghai SLAC Laboratory Animal Co., Ltd (Shanghai, China). The diets of all mice comprised $14 \%$ casein, $47 \%$ cornstarch, $15 \%$ gelatinized cornstarch, 10\% sugar, 4\% soybean oil, and $10 \%$ other (including fiber, vitamins and minerals). All animals were maintained at $24^{\circ} \mathrm{C}$ in $60 \%$ humidity in a pathogen-free environment. All the protocols in present study were approved by ethical committee of The First 
Table I. Protein levels of IFN- $\gamma$ and IL-4 in NOD mice, expressed as the mean \pm standard deviation.

\begin{tabular}{|c|c|c|c|c|}
\hline \multirow[b]{2}{*}{ Groups } & \multicolumn{2}{|c|}{$\mathrm{IFN}-\gamma, \mathrm{pg} / \mathrm{ml}$} & \multicolumn{2}{|c|}{$\mathrm{IL}-4, \mathrm{pg} / \mathrm{ml}$} \\
\hline & Serum & SG & Serum & SG \\
\hline Control & $393.62 \pm 10.16$ & $478.23 \pm 12.35$ & $66.36 \pm 3.85$ & $367.67 \pm 6.13$ \\
\hline TGP & $230.50 \pm 23.65^{\mathrm{a}, \mathrm{b}}$ & $240.24 \pm 11.67^{\mathrm{a}}$ & $48.79 \pm 5.26^{\mathrm{a}}$ & $180.21 \pm 7.96^{\mathrm{a}}$ \\
\hline $\mathrm{HCQ}$ & $282.87 \pm 9.54^{\mathrm{a}}$ & $205.18 \pm 12.63^{\mathrm{a}}$ & $53.55 \pm 6.04^{\mathrm{a}}$ & $210.44 \pm 8.74^{\mathrm{a}}$ \\
\hline Combined & $200.68 \pm 21.64^{\mathrm{a}, \mathrm{b}}$ & $112.71 \pm 15.31^{\mathrm{a}}$ & $44.16 \pm 5.88^{\mathrm{a}, \mathrm{b}}$ & $133.65 \pm 6.05^{\mathrm{a}, \mathrm{b}}$ \\
\hline
\end{tabular}

$\mathrm{n}=10$ for each group. ${ }^{\mathrm{a}} \mathrm{P}<0.05$ vs. control group; ${ }^{\mathrm{b}} \mathrm{P}<0.05$ vs. HCQ group. IFN- $\gamma$, interferon- $\gamma$; IL-4, interleukin-4; SG, submandibular gland; TGP, total glucosides of peony; HCQ, hydroxychloroquine.

Affiliated Hospital of Zhejiang University School of Medicine (Hangzhou, China).

A total of 40 NOD mice with SS were randomly assigned into 4 groups of 10 mice, as follows: i) Control group, which was fed normally; ii) TGP group, receiving $1 \mathrm{mg}$ TGP per day; iii) HCQ group, receiving $0.25 \mathrm{mg}$ hydroxychloroquine (HCQ) per day; and the iv) combined group, receiving $1 \mathrm{mg}$ TGP plus $0.25 \mathrm{mg}$ HCQ per day. After 8 weeks, blood samples were obtained from the femoral artery, the mice were euthanized by intraperitoneal injection of urethane $(2.0 \mathrm{~g} / \mathrm{kg}$; Sigma-Aldrich, St. Louis, MO, USA) and their submandibular glands were isolated for evaluation. All animal experiments complied with the experimental animal ethics guidelines of China Zoological Society.

Drugs. TGP tablets (Ningbo Lihua Pharmaceuticals Co. Ltd., Ningbo, China) were diluted in distilled water at $15 \mathrm{mg} / \mathrm{ml}$. HCQ tablets (Shanghai Zhongxi Pharmaceutical Co., Ltd., Shanghai, China) were diluted in distilled water at $3 \mathrm{mg} / \mathrm{ml}$.

Reagents. ELISA kits (Shanghai Langdun Biotechnology, Shanghai, China) were used to detect mouse IFN- $\gamma$ and IL-4 (cat. no. BP-E60055). The following primary antibodies were purchased from Santa Cruz Biotechnology, Inc. (Dallas, TX, USA): goat polyclonal anti-IFN- $\gamma$ (dilution, 1:1,000; cat. no. sc-9344), goat polyclonal anti-IL-4 (dilution, 1:1,000; cat. no. sc-1260), rabbit polyclonal anti-Fas (dilution, 1:2,000; cat. no. sc-716) and rabbit polyclonal anti-FasL (dilution, 1:2,000; cat. no. sc-956). Biotinylated goat anti-rabbit (cat. no. SP-9001) and biotinylated mouse anti-goat (cat. no. PV-9003) secondary antibodies (dilution, 1:2,000; Beijing Zhongshan Golden Bridge Biotechnology Co., Ltd., Beijing, China) were used to visualize these. A DAB substrate kit (OriGene Technologies, Inc., Beijing, China) was used to detect chemiluminescence. In situ hybridization detection kits were used in the detection of Fas and FasL (Wuhan Boshide Biological Engineering Co., Ltd., Wuhan, China).

ELISA analysis of IFN- $\gamma$ and IL-4 protein levels in serum. Blood samples were placed in serum separator tubes, maintained at room temperature for $30 \mathrm{~min}$ then centrifuged for $15 \mathrm{~min}$ at $1,400 \mathrm{x} \mathrm{g}$. Serum was transferred into a $1.5-\mathrm{ml}$ centrifuge tube and stored at $4^{\circ} \mathrm{C}$. The levels of IFN- $\gamma$ and IL-4 in the serum samples were determined using EM1001 and EMIL4 ELISA kits, respectively (Thermo Fisher
Scientific, Inc., Waltham, MA, USA), in accordance with the manufacturer's instructions.

Immunohistochemical streptavidin-peroxidase $(S-P)$ assay to evaluate IFN- $\gamma, I L-4$, Fas and FasL expression in submandibular glands. IFN- $\gamma$, IL-4, Fas and FasL protein levels in the mouse submandibular glands were determined using an immunohistochemical S-P kit (cat. no. 21124; Pierce Biotechnology, Inc., Rockford, IL, USA), in accordance with the manufacturer's instructions. Image analysis was performed using a true color multifunctional cell image analysis management system in Image-Pro Plus 7.0 (Media Cybernetics, Inc., Rockville, MD, USA). The optical densities of five randomly-selected fields were measured and their average values were used for statistical analysis.

Quantitative polymerase chain reaction ( $q P C R)$ analysis of Fas and FasL mRNA levels in submandibular glands. Briefly, total RNA was extracted using TRIzol (Beijing TransGen Biotech Co., Ltd., Beijing, China) and DNase (final concentration, 10 mM; Takara Biotechnology Co., Ltd.), and cDNA was synthesized from $1.5 \mu \mathrm{g}$ of total RNA using a Takara RNA PCR kit (AMV) v. 3.0 (Takara Biotechnology Co., Ltd.). This reverse transcription was performed in one cycle, as follows: $30^{\circ} \mathrm{C}$ for $10 \mathrm{~min} ; 42^{\circ} \mathrm{C}$ for $30 \mathrm{~min} ; 95^{\circ} \mathrm{C}$ for $5 \mathrm{~min}$; and $4^{\circ} \mathrm{C}$ for 5 min. qPCR was performed using $10 \mu \mathrm{l}$ Premix Ex Taq PCR probes (2X concentration; cat. no. RR390A; Takara

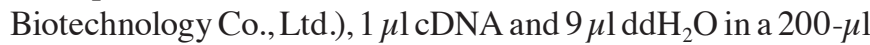
PCR tube, in accordance with the manufacturer's instructions, with GAPDH as an internal control. Primers were synthesized as follows: Fas, forward 5'-AGGCCGCCCGCTGTTTTC-3' and reverse 5'-ACGAACCCGCCTCCTCAGC-3' (product length, 145 bp); FasL, forward 5'-GCCGCCACTGACCCC TCTAA-3' and reverse 5'-CCACACTCCTCGGCTCTTTT-3' (product length, $242 \mathrm{bp}$ ); and GAPDH, forward 5'-AAATGG TGAAGGTCGGTGTG-3' and reverse 5'-TGAAGGGGTCGT TGATGG-3' (product length, $108 \mathrm{bp}$ ). PCR was conducted as follows: Incubation at $94^{\circ} \mathrm{C}$ for $5 \mathrm{~min}$, followed by 40 cycles at $94^{\circ} \mathrm{C}$ for $15 \mathrm{sec}$ and at $60^{\circ} \mathrm{C}$ for $45 \mathrm{sec}$. The fluorescence value was determined at $60^{\circ} \mathrm{C}$. These reactions were all conducted using an AriaMx Realtime PCR System (cat. no. G8830A; Agilent Technologies, Inc., Santa Clara, CA, USA).

An identical quantity of control RNA, templates and Premix Ex Taq PCR probes was used across all reactions. The average mean threshold cycle $\left(\mathrm{C}_{\mathrm{q}}\right.$ value $)$ was obtained 


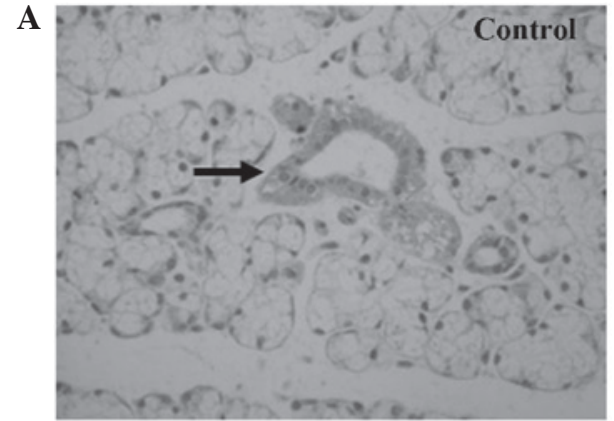

B

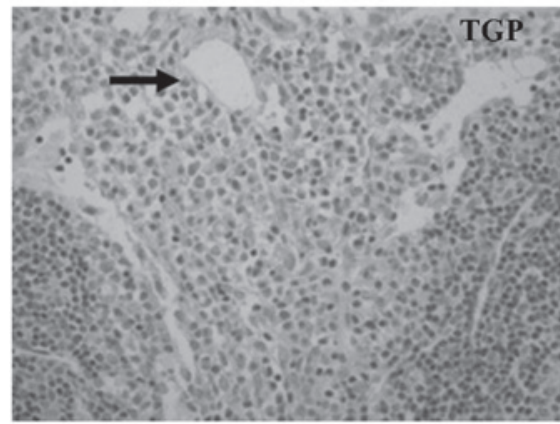

C

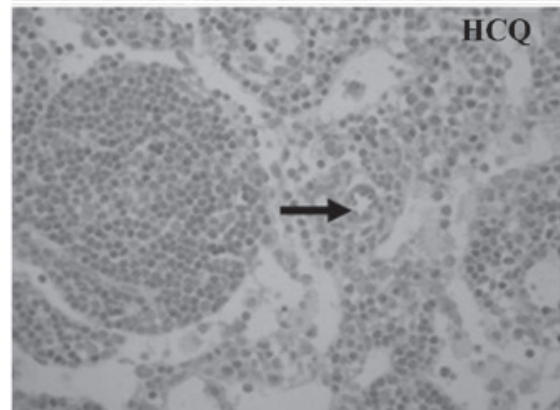

D

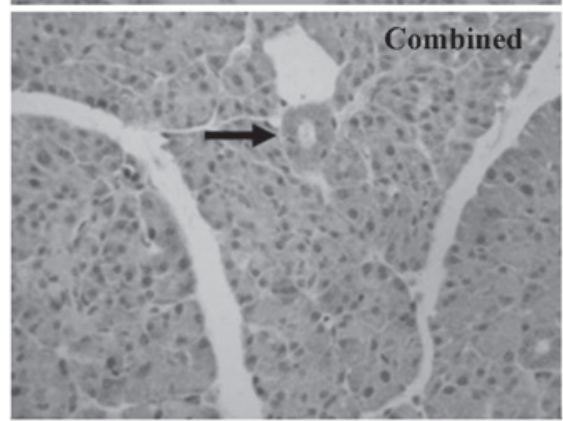

Figure 1. Immunostaining of interferon- $\gamma$ (indicated by arrows) in submandibular glands of (A) control (magnification, x400), (B) TGP (magnification, x200), (C) HCQ (magnification, x100) and (D) combined treatment group mice (magnification, x200). TGP, total glucosides of peony; HCQ, hydroxychloroquine.

and data were analyzed using the relative quantitative analysis method (14). The $2^{-\Delta \Delta C q}$ method was used to calculate relative mRNA level, and $\Delta C_{q}$ values were used for statistical analysis. The amplification and melting curves were analyzed using the AriaMx Realtime PCR System. The control untreated group and was used as a basis of comparison for the other groups.

In the present study, $\Delta \mathrm{C}_{\mathrm{q}}=\mathrm{C}_{\mathrm{q} \text { target gene }}-\mathrm{C}_{\mathrm{q} \text { internal reference gene, }}$ and $\Delta \Delta \mathrm{C}_{\mathrm{q}}=\left[\left(\mathrm{C}_{\mathrm{q} \text { target gene }}-\mathrm{C}_{\mathrm{q} \text { internal reference gene }}\right)\right.$ in the experimental group $-\left[\left(\mathrm{C}_{\mathrm{q} \text { target gene }}-\mathrm{C}_{\mathrm{q} \text { internal reference gene }}\right)\right.$ in the control group $]$. A smaller $\Delta \mathrm{C}_{\mathrm{q}}$ indicates a higher expression level of Fas and FasL mRNA in the submandibular gland tissue. A higher $2^{-\Delta \Delta \mathrm{Cq}}$ indicates a greater difference in Fas and FasL mRNA expression between the experimental and control groups.
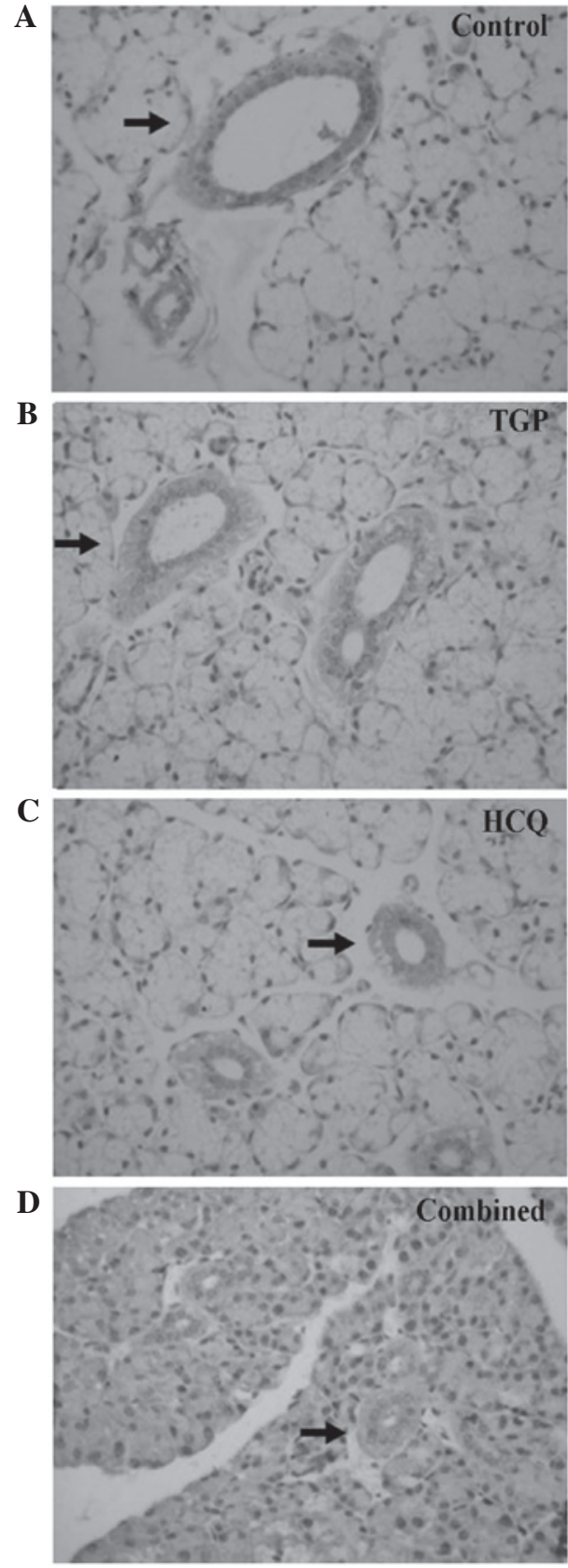

Figure 2. Immunostaining of interleukin-4 (indicated by arrows) in submandibular glands of (A) control (magnification, x400), (B) TGP, (C) HCQ and (D) combined treatment group mice (magnification, x200). TGP, total glucosides of peony; $\mathrm{HCQ}$, hydroxychloroquine.

Statistical analysis. Statistical analysis was performed using SPSS software, version 15.0 (SPSS, Inc., Chicago, IL, USA). Data are expressed as the mean \pm standard deviation. One-way analysis of variance was used to compare the groups, and the Student-Newman-Keuls method was used for post-hoc analysis. $\mathrm{P}<0.05$ was considered to indicate a statistically significant difference.

\section{Results}

TGP reduces IFN- $\gamma$ and IL-4 protein levels in NOD mice. As indicated in Table I, the levels of serum IFN- $\gamma$ and IL-4 in NOD mice were significantly higher in the control group 


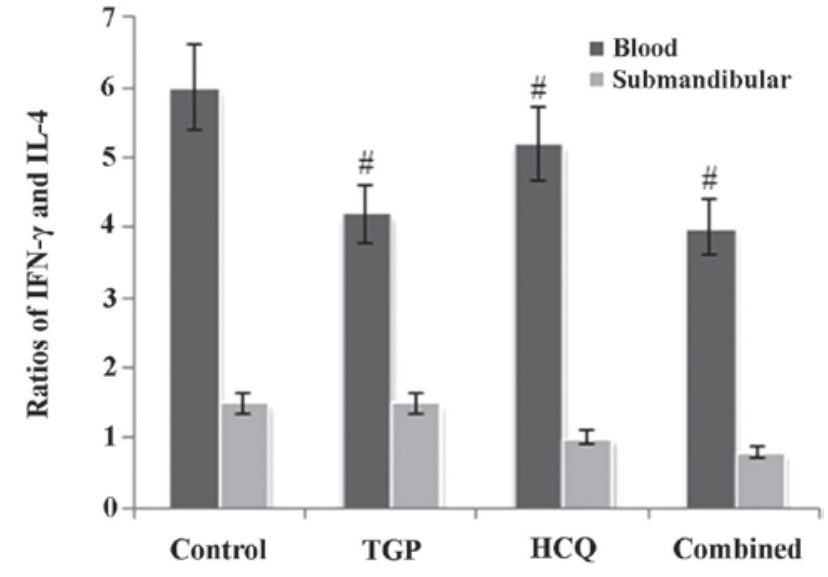

Figure 3. Ratio of IFN- $\gamma / \mathrm{IL}-4$ in serum and submandibular glands in mice. ${ }^{\#} \mathrm{P}<0.05$ vs. control group. $\mathrm{n}=10$ in each group. IFN- $\gamma$, interferon- $\gamma$; IL-4, interleukin-4; TGP, total glucosides of peony; HCQ, hydroxychloroquine.

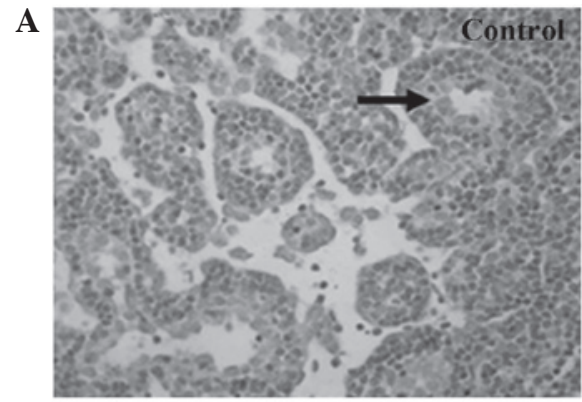

$\mathbf{B}$

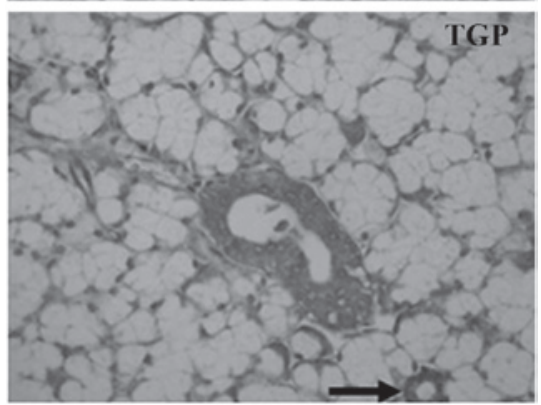

C

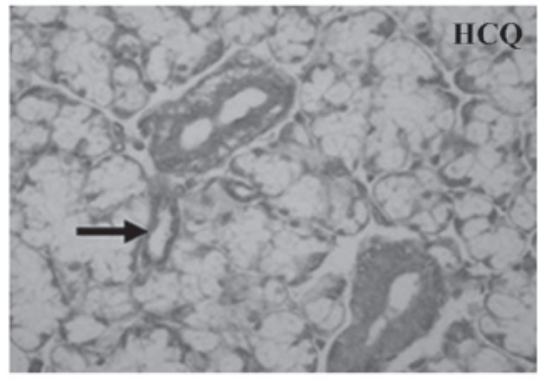

D

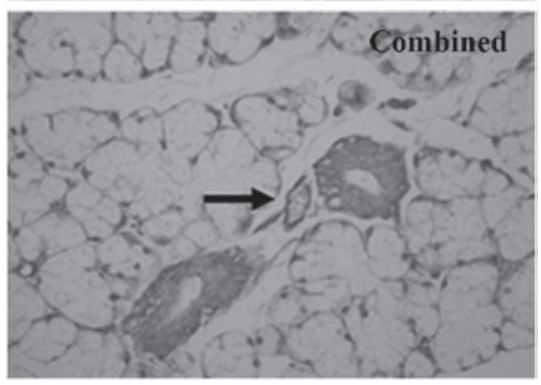

Figure 4. Immunostaining of Fas (indicated by arrows) in submandibular glands of (A) control (magnification, x100), (B) TGP, (C) HCQ and (D) combined treatment group mice (magnification, $\mathrm{x} 400$ ). TGP, total glucosides of peony; HCQ, hydroxychloroquine.
$\mathbf{A}$

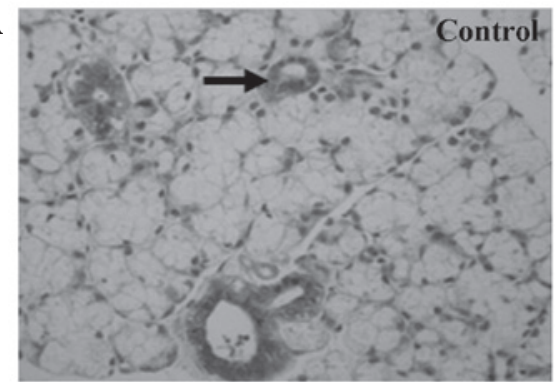

B

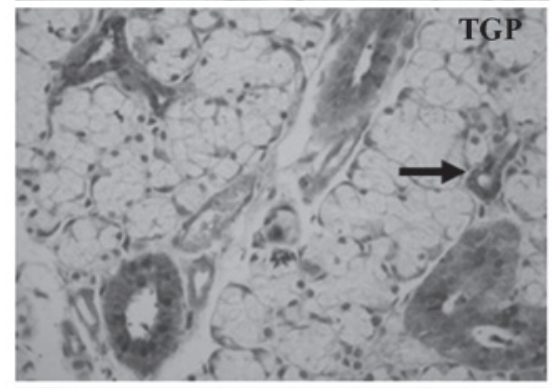

C

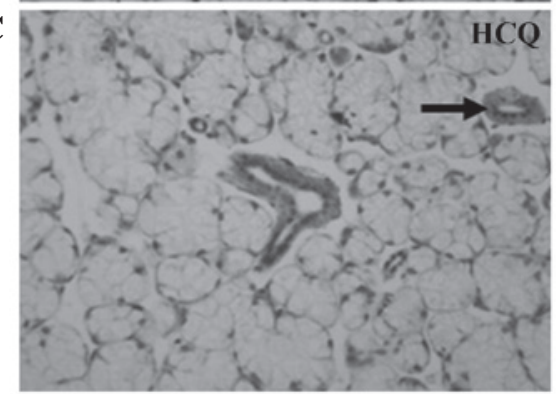

D

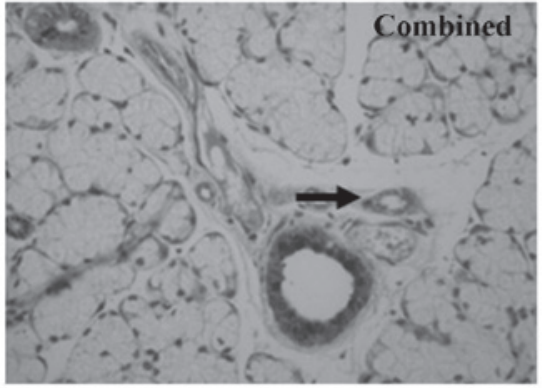

Figure 5. Immunostaining of FasL (indicated by arrows) in submandibular glands of (A) control, (B) TGP, (C) HCQ and (D) combined treatment group mice (magnification, $x 400$ ). TGP, total glucosides of peony; HCQ, hydroxychloroquine.

compared with the other groups $(\mathrm{P}<0.05)$. The levels of IFN- $\gamma$ in the TGP and combined groups were reduced compared with the HCQ group $(\mathrm{P}<0.05)$. The levels of IFN- $\gamma$ and IL-4 in the submandibular glands were increased in the control group compared with the other groups $(\mathrm{P}<0.05)$. Furthermore, the levels of IL-4 were significantly reduced in the serum and the submandibular glands in the combined group compared with the HCQ group $(\mathrm{P}<0.05)$.

As indicated by the immunohistochemical S-P assay (Figs. 1 and 2), particles of intense IFN- $\gamma$ staining were present in the apical and basolateral membranes of the submandibular gland acini, the intercalated ducts and the duct epithelia in the control NOD mice. An increased number of these IFN- $\gamma$ particles were present in the submandibular glands of the control group compared with the other groups, and fewer particles were present in a number of the intercalated ducts, duct epithelia and gland cells of the HCQ group. 
Table II. Relative mRNA levels of Fas and FasL in mouse submandibular glands

\begin{tabular}{|c|c|c|c|c|c|c|}
\hline \multirow[b]{2}{*}{ Group } & \multicolumn{2}{|c|}{$\Delta \mathrm{C}_{\mathrm{q}}$, mean $\pm \mathrm{SD}$} & \multicolumn{2}{|c|}{$\Delta \Delta \mathrm{C}_{\mathrm{q}}$, mean $\pm \mathrm{SD}$} & \multicolumn{2}{|c|}{$2^{-\Delta \Delta C q}$} \\
\hline & Fas & FasL & Fas & FasL & Fas & FasL \\
\hline Combined & $6.91 \pm 1.23^{\mathrm{a}, \mathrm{b}}$ & $10.13 \pm 1.03^{\mathrm{a}, \mathrm{b}}$ & $0.00 \pm 1.74$ & $0.00 \pm 1.46$ & 1.000 & 1.000 \\
\hline HCQ & $12.53 \pm 1.87$ & $13.93 \pm 2.36$ & $5.62 \pm 2.24$ & $3.80 \pm 2.57$ & 0.020 & 0.072 \\
\hline TGP & $9.23 \pm 1.35^{\mathrm{a}, \mathrm{b}}$ & $11.38 \pm 1.69^{\mathrm{a}}$ & $2.32 \pm 1.83$ & $1.25 \pm 1098$ & 0.200 & 0.420 \\
\hline Control & $13.26 \pm 1.68$ & $15.25 \pm 3.18$ & $6.35 \pm 2.08$ & $5.12 \pm 3.34$ & 0.012 & 0.029 \\
\hline
\end{tabular}

$\mathrm{n}=10$ in each group. ${ }^{\mathrm{a}} \mathrm{P}<0.05$, vs. control group; ${ }^{\mathrm{b}} \mathrm{P}<0.05$ vs. HCQ group. SD, standard deviation; TGP, total glucosides of peony; HCQ, hydroxychloroquine.

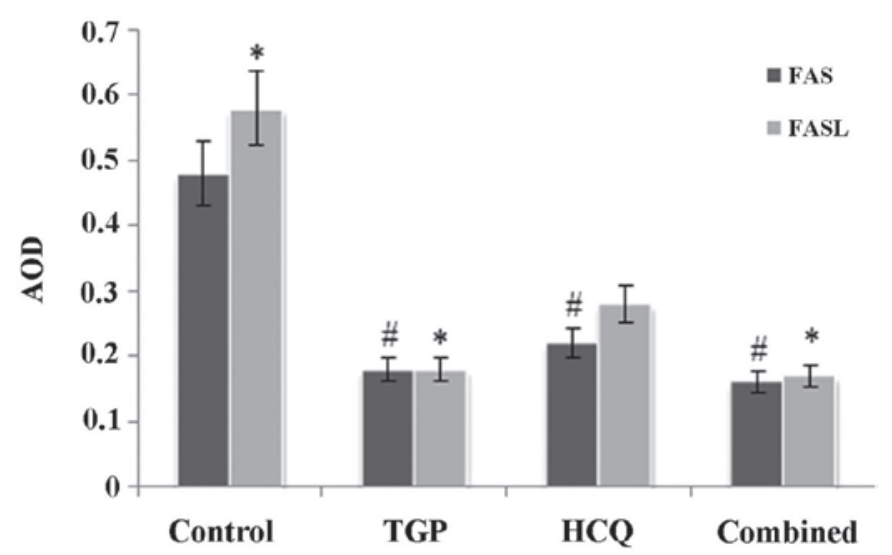

Figure 6. Fas and FasL levels in mouse submandibular glands. ${ }^{\text {}} \mathrm{P}<0.05$ vs. control group; ${ }^{*} \mathrm{P}<0.05$ vs. HCQ group. $\mathrm{n}=10$ in each group. AOD, average optical density; TGP, total glucosides of peony; HCQ, hydroxychloroquine.

However, the IFN- $\gamma$ staining in the HCQ-treated group was more intense compared with the combined group. Marked expression of IL-4 particles was detected in the basement membrane of the submandibular gland acini and ducts in the control group. Diffuse staining was observed in the basement membrane of submandibular gland acini and ducts in all groups, with less intense expression observed in the combined and TGP groups.

TGP reduces the ratio of $I F N-\gamma$ to $I L-4$ in NOD mice. As reported in Fig. 3, the ratio of IFN- $\gamma$ to IL-4 in mouse serum was higher in the control group compared with the other groups $(\mathrm{P}<0.05)$. In addition, the ratio of IFN- $\gamma$ to IL-4 in the submandibular glands of the control group mice was increased compared with the other groups; however, this difference was not statistically significant $(\mathrm{P}>0.05)$.

TGP reduces Fas and FasL protein levels in mouse submandibular glands. Fas and FasL expression was detected using immunohistochemical staining (Figs. 4 and 5). High levels of Fas and FasL were observed in the cytoplasm and membrane of submandibular gland cells and in the duct epithelia of the control mice. Diffuse expression of Fas and FasL in the cytoplasm and on the membrane of submandibular gland cells and in the duct epithelia of the mice was also observed in the TGP,
HCQ and combined groups; however, FasL expression in these groups was lower compared with the control group.

As shown in Fig. 6, the expression of Fas and FasL proteins in the submandibular glands was significantly increased in the control group compared with the other groups $(\mathrm{P}<0.05)$. There was no statistical difference in the expression of Fas protein amongst the 3 treatment groups, whilst FasL protein expression was significantly lower in the TGP group compared with the HCQ group $(\mathrm{P}<0.05)$. FasL protein expression was significantly lower in the combined group compared with the HCQ group $(\mathrm{P}<0.05)$.

TGP reduces the levels of Fas and FasL mRNA in mouse submandibular glands. The amplification curves of Fas and FasL mRNA in all samples indicated exponential growth, eventually reaching a plateau, indicative of its high-efficiency amplification. The melting curves for Fas mRNA and FasL PCR products presented with a single peak, indicating a single amplification product (data not shown).

As demonstrated in Table II, the levels of Fas mRNA in mouse submandibular glands were significantly increased in the control group compared with the combined and TGP groups $(\mathrm{P}<0.05)$. Furthermore, Fas mRNA levels were lower in the TGP and combined groups compared with the HCQ group $(\mathrm{P}<0.05)$.

The levels of FasL mRNA in mouse submandibular glands were significantly higher in the control group compared with the combined and TGP groups $(\mathrm{P}<0.05)$. The relative mRNA levels of FasL mRNA were significantly lower in the combined group compared with the HCQ group $(\mathrm{P}<0.05)$.

\section{Discussion}

Previous pharmacological studies have demonstrated that TGP is able to exert bidirectional immunomodulatory, anti-inflammatory, anti-oxidative and analgesic effects $(15,16)$. TGP has been repeatedly used in the treatment of SS, with effective clinical results (3). The combined use of TGP and HCQ, however, may have more significant therapeutic effects in the treatment of SS. A combined therapy may reduce ESR, improve symptoms including a dry mouth and eyes and can increase saliva flow with reduced side effects (17). Therefore, the present study aimed to elucidate the molecular mechanism underlying this combination treatment. SS has complex 
clinical manifestations, and there is currently no uniform classification criterion for SS (18). Previous studies have primarily relied on animal models to investigate the pathogenesis and treatment of SS (19). The NOD mouse frequently develops insulin-dependent diabetes and lymphocytic infiltration in the submandibular and lacrimal glands and other organs (20). These types of pathological damage are similar to those observed in SS. The NOD mouse is therefore an appropriate animal model for the study of SS (21).

SS is a chronic systemic autoimmune disease that affects the exocrine glands, including salivary and lacrimal glands; and the majority of patients with SS are women aged 40-50 years (22). Currently, the etiology and pathogenesis of SS is unclear, and there is no specific treatment for SS. There has been increased attention directed towards the immune effects of the helper T cells (Th) and cytokines secreted by Th cells in patients with SS and in animal models. During the onset of SS, Th1- and Th2-type cytokines are in a state of dynamic equilibrium. Th2-type cytokines are dominant during the early stages of lymphocytic infiltration into the exocrine glands in patients with SS (23). However, Th1-type cytokines gradually become more involved during the late stage of SS, when infiltration becomes more severe (24). A previous study revealed that the levels of Th1-type cytokine IFN- $\gamma$ and tumor necrosis factor- $\alpha$ (TNF- $\alpha$ ) in the salivary glands are significantly higher in patients with SS compared with normal control patients (25). IFN- $\gamma$ is able to reduce the growth and development of salivary gland cells, thus serving an crucial function in early SS onset (26). Cytokine IL-4, secreted by Th2 cells, has a key role in the adaptive immune response during clinical onset of SS, and the knocking out of IL-4 genes has been demonstrated to restore gland secretory functions in SS animal models (6). Previous experiments by the authors of the current study have demonstrated that the levels of Th1- and Th2-specific cytokines in serum and submandibular glands of NOD mice were significantly increased compared with normal BALB/C mice, indicating a Th1/Th2 immune imbalance (8).

Fas and its ligand FasL are crucially involved in the regulation of apoptosis, immune privilege and the maintenance of homeostasis in the body (27). Previous studies have demonstrated that Fas expression in SS exocrine epithelial cells and the classical Fas/FasL system, induce apoptosis, causing human placental and gestational trophoblastic disease (28). Saegusa et al (29) reported $\mathrm{CD}^{+}{ }^{+} \mathrm{T}$ cell infiltration in salivary gland tissue and large ratio of Fas to FasL ligands in an SS animal model, but that salivary duct epithelial cells continue to secrete Fas. These results suggested that Fas/FasL pathway-mediated apoptosis may be partially responsible for labial gland tissue destruction and dysfunction in SS.

Thl cells are able to induce apoptosis of target cells by expressing FasL (30). Fas mRNA is predominantly expressed in Th2 cells, and FasL mRNA in Thl cells. Thl cells are able to downregulate Th 2 and Th 0 cells by Fas/FasL-mediated apoptosis; however, imbalance of Thl to Th 2 cells causes changes to cytokine secretion and inhibits the normal apoptosis of immune cells, leading to the accumulation of nucleosomes in cells (31). These nucleosomes subsequently stimulate the production of antibodies by autoreactive T-lymphocytes, thereby damaging the body. The combined effects of Th1 and Th2 cells regulate the onset of SS. Previous studies have suggested that the
Fas to FasL ratio is correlated with the IFN- $\gamma$ to IL-4 ratio in SS labial gland lymphocytes, and is positively correlated with lymphocyte infiltration in labial glands (32). These results suggest that the increase in IFN- $\gamma$ to IL-4 and Fas to FasL ratio is crucially involved in the destruction of SS labial glands and pathogenesis of SS.

The present study demonstrated that the levels of IFN- $\gamma$ and IL-4 in serum and in submandibular glands were significantly higher in the control NOD mice compared with the other groups. However, IFN- $\gamma$ levels in serum were lower in the TGP and combined groups compared with the HCQ group. The ratio of IFN- $\gamma$ to IL-4 in serum was higher in the control group compared with the TGP, HCQ and combined groups. Following TGP intervention, the expression of Fas and FasL in the submandibular glands reduced, and the expression of Fas and FasL mRNA in the submandibular glands was significantly lower in the TGP group compared with the control group. These results suggest that TGP is able to reduce cytokine levels in serum and submandibular glands in SS, and decrease the ratio of IFN- $\gamma$ to IL-4 in submandibular glands. Furthermore, TGP appears to be able to downregulate the levels of Fas, FasL and their mRNA expression, thereby mediating the Th1/Th2 immune balance and reducing cell apoptosis, thus achieving its therapeutic effect on SS. Future studies are required to aid understanding of the mechanism by which TGP affects cell apoptosis.

\section{References}

1. Wang Y and Wang Y: Pharmacological study and clinical application of total glucosides of peony in autoimmune diseases. Zhe Jiang Zhong Yi Yao Da Xue Xue Bao 2: 240-241, 244, 2007 (In Chinese).

2. Zhang HF, Hou P and Xiao WG: Clinical observation on effect of total glucosides of paeony in treating patients with non-systemic involved Sjogren syndrome. Zhong Guo Zhong Xi Yi Jie He Za Zhi 27: 596-598, 2007 (In Chinese).

3. Li X, Li X, Wang G, Qian L and Wang Z: Effectiveness and safety of total glucosides of peony in the treatment of patients with Sjogren syndrome. An Hui Yi Xue 5: 370-371, 2006 (In Chinese).

4. Wu GL, Pu XH, Yu GY and Li TY: Effects of total glucosides of peony on AQP-5 and its mRNA expression in submandibular glands of NOD mice with Sjogren's syndrome. Eur Rev Med Pharmacol Sci 19: 173-178, 2015.

5. Carsons SE: Issues related to clinical trials of oral and biologic disease-modifying agents for Sjogren's syndrome. Rheum Dis Clin North Am 34: 1011-1023, 2008.

6. Nguyen CQ, Gao JH, Kim H, Saban DR, Cornelius JG and Peck AB: IL-4-STAT6 signal transduction-dependent induction of the clinical phase of Sjögren's syndrome-like disease of the nonobese diabetic mouse. J Immunol 179: 382-390, 2007.

7. Munder M, Eichmann K and Modolell M: Alternative metabolic states in murine macrophages reflected by the nitric oxide synthase/arginase balance: Competitive regulation by CD4+ T cells correlates with Th1/Th2 phenotype. J Immunol 160: 5347-5354, 1998.

8. Choi YJ, Saez B, Anders L, Hydbring P, Stefano J, Bacon NA, Cook C, Kalaszczynska I, Signoretti S, Young RA, Scadden DT, et al: D-cyclins repress apoptosis in hematopoietic cells by controlling death receptor Fas and its ligand FasL. Dev Cell 30: 255-267, 2014.

9. Elmansy H, Kotb A, Hammam O, Abdelraouf H, Salem H, Onsi M, Elleithy T: Prognostic impact of apoptosis marker Fas (CD95) and its ligand (FasL) on bladder cancer in Egypt: Study of the effect of schistosomiasis. Ecancermedicalscience 6: 278, 2012.

10. Nakajima H and Oka T: Analysis of biochemical and biological functions of Fas-ligand (FasL) and Fas on activated T cells in allo-immune response. Transplant Proc 29: 1096-1100, 1997. 
11. Riddell SR, Elliott M, Lewinsohn DA, Gilbert MJ, Wilson L, Manley SA, Lupton SD, Overell RW, Reynolds TC, Corey L and Greenberg PD: T cell mediated rejection of gene modified HIV specific cytotoxic T lymphocytes in HIV infected patients. Nat Med 2: 216-223, 1996.

12. Wu GL, Li TY, Lu WW, Yu GY and Fan YS: Effect of nourishing Yin, strengthening Qi and activating blood decoction on Fas/FasL in salivary glands of NOD mice with Sjogren's syndrome and their mRNA expression. Zhong Guo Zhong Yao Za Zhi 38: 4148-4151, 2013 (In Chinese).

13. Tzioufas AG, Kapsogeorgou EK and Moutsopoulo HM: Pathogenesis of Sjögren's syndrome: What we know and what we should learn. J Autoimmun 39: 4-8, 2012.

14. Jin L, Lloyd RV, Nassar A, Lappinga PJ, Sebo TJ, Swartz K, Seys AR, Erickson-Johnson MR, Roth CW, Evers BR, et al: HMGA2 expression analysis in cytological and paraffin-embedded tissue specimens of thyroid tumors by relative quantitative RT-PCR. Diagn Mol Pathol 20: 71-80, 2011.

15. Kim SH, Lee MK, Lee KY, Sung SH, Kim J and Kim YC: Chemical constituents isolated from Paeonia lactiflora roots and their neuroprotective activity against oxidative stress in vitro. J Enzyme Inhib Med Chem 24: 1138-1140, 2009.

16. Zhou X, Ding J, Zhu M, Mou C, Wang H, Wang Y, He J, Chen R, Gao X and Yang Z: The effects on TNF- $\alpha$ and sICAM-1 in the adjuvant arthritis rat model by the total glucosides of peony. Xin Jiang Yi Ke Da Xue Xue Bao 12: 1677-1679, 2009 (In Chinese).

17. Pijpe J, van Imhoff GW, Spijkervet FK, Roodenburg JL, Wolbink GJ, Mansour K, Vissink A, Kallenberg CG and Bootsma H: Rituximab treatment in patients with primary Sjögren's syndrome: An open-label phase II study. Arthritis Rheum 52: 2740-2750, 2005.

18. Plešivčnik Novljan M, Rotar Z, Ambrožič A, Vidmar G and Tomšič M: Comparison of the performance of the different classification criteria for primary Sjögren's syndrome: A prospective cohort study. Clin Rheumatol 33: 1657-1664, 2014.

19. Shi H, Yu CQ, Xie LS, Wang ZJ, Zhang $\mathrm{P}$ and Zheng LY: Activation of TLR9-dependent $\mathrm{p} 38 \mathrm{MAPK}$ pathway in the pathogenesis of primary Sjögren's syndrome in NOD/Ltj mouse. J Oral Pathol Med 43: 785-791, 2014.

20. Asamoto H, Akazawa Y, Tashiro S, Oishi M, Azuma T, Koide S, Sudo K, Yokota $\mathrm{H}$ and Tochino Y: Infiltration of lymphocytes in various organs of the NOD (non-obese diabetic) mouse. J Jpn Diabetes Soc 27: 775-781, 1984

21. Wang D, Xue L, Yang Y, Hu J, Li G and Piao X: Temporal gene expression analysis of Sjögren's syndrome in C57BL/6. NOD-Aec1Aec2 mice based on microarray time-series data using an improved empirical Bayes approach. Mol Biol Rep 41: 5953-5960, 2014
22. Vale DL: Recognition and management of Sjögren's syndrome: Strategies for the advanced practice nurse. Nurs Clin North Am 35: 267-278, 2000.

23. Ramos-Casals M, Garcia-Carrasco M, Cervera R, Filella X, Trejo O, de la Red G, Gil V, Sánchez-Tapias JM, Font J and Ingelmo M: Th1/Th2 cytokine imbalance in patients with Sjögren syndrome secondary to hepatitis $\mathrm{C}$ virus infection. Semin Arthritis Rheum 32: 56-63, 2002.

24. Mitsias DI, Tzioufas AG, Veiopoulou C, Zintzaras E, Tassios IK, Kogopoulou O, Moutsopoulos HM and Thyphronitis G: The Th1/Th2 cytokine balance changes with the progress of the immunopathological lesion of Sjogren's syndrome. Clin Exp Immunol 128: 562-568, 2002.

25. Kang EH, Lee YJ, Hyon JY, Yun PY and Song YW: Salivary cytokine profiles in primary Sjögren's syndrome differ from those in non-Sjögren sicca in terms of TNF- $\alpha$ levels and Th-1/Th-2 ratios. Clin Exp Rheumatol 29: 970-976, 2011.

26. Mariette X: Pathophysiology of Sjogren's syndrome. Ann Med Interne (Paris) 154: 157-168, 2003 (In French).

27. Nagarkatti N: Tumor-derived Fas ligand induces toxicity in lymphoid organs and plays an important role in successful chemotherapy. Cancer Immunol Immunother 49: 46-55, 2000.

28. Mor G, Gutierrez LS, Eliza M, Kahyaoglu F and Arici A: Fas-fas ligand system-induced apoptosis in human placenta and gestational trophoblastic disease. Am J Reprod Immunol 40: 89-94, 1998.

29. Saegusa K, Ishimaru N, Yanagi K, Mishima K, Arakaki R, Suda T, Saito I and Hayashi Y: Prevention and induction of autoimmune exocrinopathy is dependent on pathogenic autoantigen cleavage in murine Sjögren's syndrome. J Immunol 169: 1050-1057, 2002.

30. Zhang X, Brunner T, Carter L, Dutton RW, Rogers P, Bradley L, Sato T, Reed JC, Green D and Swain SL: Unequal death in T helper cell (Th)1 and Th2 effectors: Th1, but not Th2, effectors undergo rapid Fas/FasL-mediated apoptosis. J Exp Med 185: 1837-1849, 1997.

31. Yung R, Kaplan M, Ray D, Schneider K, Mo RR, Johnson K and Richardson B: Autoreactive murine Th1 and Th2 cells kill syngeneic macrophages and induce autoantibodies. Lupus 10: 539-546, 2001.

32. Zhou Q, Bai T and Wu H: Expression of Th1/Th2 and Fas/FasL in the labial salivary gland of patients with Sjögren's syndrome and its significance. Xu Zhou Yi Xue Yuan Xue Bao 28: 28-30, 2008 (In Chinese). 